\title{
REFLEXIONES SOBRE LAS BASES DE LA POLÍTICA CRIMINAL
}

\author{
Jesús-María Silva Sánchez \\ Catedrático de Derecho Penal \\ Universidad Pompeu Fabra.
}

\section{La administración de la herencia determinista de von Liszt.}

1. Franz von Liszt creó la Política criminal como disciplina científica ${ }^{1}$, concibiéndola como el conjunto de criterios determinantes de una lucha "eficaz" contra el delito ${ }^{2}$. Su punto de partida, como es sabido, era una concepción determinista del hombre, una visión del delito como reflejo de la peligrosidad del mismo (social e individualmente determinada $)^{3}$ y una fe positivista en la posibilidad de corregir los factores individuales (por la psiquiatría o la instrucción) y las estructuras sociales (por la política social) que conducen al delito. Por todo ello, su planteamiento de la Política criminal "empírica" es expresión clara de la ideología terapéutica de finales del S. XIX; se parte del diagnóstico de la Criminología empírica y se responde con la terapia de la Penología, con el peculiar concepto que de la misma tiene el propio von Liszt.

"Die Kriminalpolitik, so wie wir sie verstehen, ist bedingt durch den Glauben an die Verbesserungsfähigkeit des Menschen, des einzelnen, wie der Gesellschaft" 4 .

2. Lo anterior sólo puede resultar una novedad para quienes únicamente estén familiarizados con el von Liszt del "Lehrbuch", que comúnmente se asocia al concepto

${ }^{1}$ Al respecto señala RADBRUCH, Recensión a la $21^{3}$ y $22^{2}$ edición del Tratado de von Liszt, en RADBRUCH, Gesamtausgabe 7, Strafrecht I. Heidelberg 1995, p. 269: "Franz v. Liszts Strafrechtslehrbuch bedeutet in der langen Reihe seiner Auflagen die Geschichte der deutschen Strafechtswissenschaft durch nahezu vier Jahrzehnte, wie Franz v. Liszts strafrechtliche Aufsätze und Vorträge das Urkundenbuch zur Geschichte der modernen Kriminalpolitik sind".

${ }^{2}$ VON LISZT, "Die Aufgaben und die Methode der Strafrechtswissenschaft", ZStW 20 (1900), pp. 161 y s5., 172: a la Política Criminal le corresponde la "misión política" de una "Weiterbildung der Gesetzgebung im Sinne einer ZielbewuBten Bekämpfung des Verbrechens, insbesondere auch, aber nicht ausschließlich, durch die Strafe und die mit ihr verwandten Maßregeln".

${ }^{3}$ Como apunta VON LISZT, "Die determitistischen Gegner der Zweckstrafe (1893)", en Strafrechtliche Aufsätze und Vorträge, tomo 2, Berlin 1905, pp. 25 y ss., 65, el delito, como toda acción humana es la consecuencia necesaria "aus der teils angebotenen, teils erworbenen Eigenart des Täters einerseits, der ihn im Augenblick der Tat umgebenden gesellschaftlichen, insbesondere wirtschaftlichen Verhältnisse andererseits".

${ }^{4}$ VON LISZT, "Die Zukunft des Strafrechts (1892)", en Strafrechtliche Aufsätze und Vorträge, tomo 2, Berlin 1905, pp. 1 y ss., 23-24. 
clasificatorio del delito (de raigambre causalista-naturalista). Al respecto, conviene no ignorar la profunda cesura que existe entre el Liszt dogmático y el Liszt políticocriminal $^{5}$. El primero, es un autor que en su Tratado (desde 1881) describe y sistematiza el Código penal alemán de 1871; pero, que despectivamente entiende la dogmática como una disciplina inferior, dedicada a explicar sistemáticamente el Código a los estudiantes de Derecho. El segundo es quien, a la vez, desde el Programa de Marburgo (1882) desarrolla una concepción político-criminal basada en la ideología terapéutica y, en última instancia, en la sustitución de la pena y del Derecho penal de la culpabilidad por la medida de seguridad y el Derecho penal de la peligrosidad. En el marco de esta dualidad, adquiere probablemente todo el sentido su frase tantas veces citada de que el Derecho penal -es decir, el StGB de 1871- es la "unübersteigbare Schranke der Kriminalpolitik" ${ }^{\prime \prime}$. En otras palabras, que la política criminal eficaz por él preconizada debe ser, al menos por el momento, contenida, porque no es la acogida en el Código vigente?

3. Dado que la Política criminal "científica" surge de la mano de von Liszt, es hasta cierto punto lógico que muchos asocien también el contenido de la Política criminal a la ideología terapéutica y al intervencionismo penal que caracterizaban la propia concepción de von Liszt sobre la misma ${ }^{8}$. Por otro lado, debe concederse que ésta, de entrada, tuvo connotaciones prestigiosas ${ }^{9}$ : era el momento en que la

${ }^{5}$ Como señala RADBRUCH, Recensión a la $21^{z}$ y $22^{a}$ edición del Tratado de von Liszt, en RADBRUCH. Gesamtausgabe 7, Strafrecht I, Heidelberg 1995,p. 271 : "Es ist kein Zufall, daß gerade Liszt, dessen Kriminalpolitik die verbrecherische Gesinnung so entschiden zum Ausgangspunkt nimmt, sein Strafrechtssystem mit derselben Entschiedenheit auf der verbrecherischen Handlung aufbaut. Dieser scheinbare Widerspruch ist vielmehr nur eine Teilerscheinung des großen Gegensatzes, in den Liszts gesamtes kriminalpolitisches Denken eingespannt ist: des Gegensatzes zwischen Sicherungstheorie und Rechtssicherheitsgedanke".

${ }^{6}$ VON LISZT, "Über den Einfluß der soziologischen und anthropologischen Forschungen auf die Grundbegriffe des Strafrechts (1893)", en Strafrechtliche Aufsätze und Vorträge, tomo 2, Berlin 1905, pp. 75 y ss., 80.

${ }^{7}$ Es interesante que la difundida expresión de von Liszt sobre el Derecho penal como "Magna Charta" ni siquiera aparezca en el Programa de Marburgo, porque éste se entiende perfectamente sin legalidad: cfr. EHRET, Franz von Liszt und das Gesetzlichkeitsprinzip. Zugleich ein Beitrag wider die Gleichstellung von Magna-charta-Forme und Nullum-crimen-Satz, Frankfurt 1996, pp. 103 y ss, 149, 206. Y es que, en realidad, la vinculación a la ley había de entenderse más bien como un obstáculo en el marco de la concepción político-criminal de von Liszt, que, orientada a la "Zweckrationalität". demandaba coherentemente flexibilidad. Lo más importante es, pues, subrayar la gran distancia que separa a von Liszt de Feuerbach en este punto (pp. 205-206).

${ }^{8}$ Ehret, Franz von Liszt, pp. 177 y ss, pone de relieve cómo la acogida de la sentencia indeterminada por parte de Liszt supone la opción por una más eficaz represión de la criminalidad, frente a la seguridad jurídica y el principio de culpabilidad.

${ }^{9}$ Como es lógico, si se tiene en cuenta el clima cultural por aquel entonces existente y, por otro lado, el enorme prestigio de la figura de von Liszt, cuya obra (en las sucesivas ediciones del Tratado y en sus estudios concretos compilados en 1905) marca entre treinta y cuarenta años clave en el desarrollo de la ciencia penal contemporánea. Por ello, no extraña que RADBRUCH, Recensión a la $21^{2}$ y $22^{2}$ edición del Tratado de von Liszt, en RADBRUCH, Gesamtausgabe 7. Strafrecht I. Heidelberg 1995, p. 274, concluya afirmando que "das wissen wir bestimmt, daß Liszts Gedanken in den Köpfen auch noch fortleben und fortwirken werden, wenn einmal die Erinnerung des Menschen entschwinden sollte, daß es Liszts Gedanken waren". 
sustitución de la pena por la medida de seguridad y la del jurista por el médico se planteaban como una opción humanista y de progreso.

4. Ahora bien, el paso del tiempo -y el advenimiento de los totalitarismos de todo signo, que hicieron suya la Política criminal intervencionista-terapéutica- modificó ese juicio inicial. Y se advirtió cómo, en contra de lo que cabía esperar, la exclusiva referencia del Derecho penal al cumplimiento de supuestas funciones socio-terapéuticas no implicaba su restricción, sino precisamente su ampliación a niveles hasta entonces desconocidos ${ }^{10}$. Es más, esta referencia a las funciones socio-terapéuticas del Derecho penal sigue siendo hoy el punto de partida para todas las tendencias expansionistas del Derecho penal ${ }^{11}$. Es lo que Hassemer denomina el "Derecho penal curativo", en el que el Derecho penal ya no se manifiesta como verdugo, sino como médico ${ }^{12}$, con lo que las prevenciones de todo signo que cabía oponer frente a aquél se desvanecen ante la perspectiva curativa, que se manifiesta entonces en toda su potencia antiliberal.

5. En todo caso, el modelo intervencionista del Derecho penal del autor peligroso no se mantuvo. Ello, ya antes de la Il Guerra Mundial, en el marco de la propia República de Weimar, donde quedó claramente consagrado el sistema de la doble vía ${ }^{13}$. Por lo demás, la inmediata postguerra sumió en el descrédito este modelo, que ya nunca se mantuvo en sus pretensiones iniciales: así, ni el movimiento de la llamada defensa social ni, mucho menos, la nueva defensa social eran ya más que epígonos muy debilitados de lo anterior. Caso distinto es el de los Estados Unidos, donde las ideas utilitaristas que sirven de base a esta concepción (incapacitation.

\footnotetext{
${ }^{10}$ Muy instructivo, por otros muchos, PASUKANIS, Teoría general del Derecho y marxismo (present. y trad. Virgilio Zapatero), Barcelona 1976, pp. 143 y ss., 153. "Si reemplazamos la pena por la Behandlung (en ruso, medida de influencia), es decir, por un concepto jurídicamente neutral médico-pedagógico, se llega a resultados completamente diferentes. En este caso no será la proporcionalidad de la pena la que nos preocupará por encima de todo sino la adecuación de las medidas al fin fijado, es decir, a los fines de defensa de la sociedad, influencia sobre el delincuente, etc. Según este punto de vista la relación puede ser completamente invertida: en el caso precisamente de una responsabilidad atenuada pueden ser necesarias las medidas más largas y las más intensas": 154: "El capitalismo industrial, la declaración de los derechos del hombre, la economía politica de Ricardo y e sistema de detención temporal son fenómenos que pertenecen a una única y misma época histórica"; 157 y ss. 159: "En realidad una aplicación coherente del principio de defensa de la sociedad no exigiría la fijación de cada supuesto de hecho legal penal (a los cuales se refieren lógicamente las medidas de la pena fijadas por la ley o por el tribunal), sino una descripción precisa de los síntomas que caracterizan el estado socialmente peligroso y una elaboración precisa de los métodos a aplicar en cada caso particular para proteger a la sociedad".

${ }^{11}$ SCHEERER, "Strafe muß sein! Muß Strafrecht sein?", en BÖLLINGER/LAUTMANN (Hrsg.), Vom Guten, das noch stets das Böse schafft. Kriminalwissenschaftliche Essays zu Ehren von Herbert Jäger. Frankfurt 1993, pp. 69 y ss., 75-76

12 HASSEMER, "Bilder vom Strafrecht", en BÖLLINGER/LAUTMANN (Hrsg.), Vom Guten, das noch stets das Böse schafft. Kriminalwissenschaftliche Essays zu Ehren von Herbert Jäger. Frankfurt 1993, pp. 235 y ss., 241 y ss. Un Derecho penal "curativo" elude, ciertamente, muchos problemas de legitimación y, por añadidura, muchas críticas.

${ }^{13} \mathrm{Cfr}$. el análisis y crítica de MUÑOZ CONDE, "Política criminal y dogmática jurídico-penal en la República de Weimar", en Doxa 15-16 (1994), pp. 1025 y ss., 1031
} 
rehabilitation, deterrence) se habían plasmado en modelos (como el de la sentencia indeterminada) bastante cercanos a la ideología aludida ${ }^{14}$.

6. En los últimos años cincuenta y primeros sesenta, con ocasión del proceso de reforma penal alemana, vuelve a hablarse, con todo, en el círculo de los "profesores alternativos", de un retorno a von Liszt ${ }^{15}$. Ahora bien, como sucede en todos los retornos, tampoco aquí se retoma al von Liszt originario. Así, ciertamente se pretende retomar el discurso de la función socio-terapéutica del Derecho penal. Pero ya no es la eficacia el único criterio de racionalidad en la lucha contra el delito, sino que se introducen otros principios de autocontención. El discurso político-criminal de la reforma asume así dos referentes de racionalidad: uno empírico, de eficacia, y otro valorativo, de garantías ${ }^{16}$. De este modo surge la Política criminal valorativa, que ha marcado los últimos treinta años. Unos años durante los cuales, sin embargo, se han ido disolviendo sus dos ejes fundamentales: la fe en la resocialización y, también, la convicción acerca de la inconmovibilidad de las garantías. En cambio, se ha ido asentando una Política criminal "práctica" de orientación intimidatoria e inocuizadora, en un contexto general presidido por la oportunidad y el populismo. Seguramente no es exagerado afirmar que, con ello, la situación del Derecho penal se está haciendo insostenible ${ }^{17}$. Ahora más que nunca debe, pues, hacerse hincapié en la necesidad de orientar la Política criminal a la los principios que derivan de la idea de dignidad de la persona.

\section{Sobre la idea de "Política criminal".}

1. De entrada, es necesario, por tanto, distinguir categóricamente entre la praxis de la Política Criminal y una Política criminal teórica ${ }^{18}$. La primera se integra del conjunto de actividades -empíricas- organizadas y ordenadas a la protección de individuos y sociedad en la evitación del delito ${ }^{19}$. La segunda aparece constituida por un

${ }^{14} \mathrm{Cfr}$. la reveladora exposición resumida de BRAITHWAITE/PETTIT, Not Just Deserts. A Republican Theory of Criminal Justice, Oxford 1990, p. 3-4.

${ }^{15}$ Uno de los trabajos paradigmáticos es el de KLUG, "Abschied von Kant und Hegel", en Baumann (Hrsg.). Programme für ein neues Strafgesetz, Frankfurt 1968, pp. 36 y ss. Cfr, también AA.VV, La funzione della pena, il commitato de Kant e de Hegel, Milano 1989.

${ }^{16}$ Una perspectiva a la que contribuye de modo esencial toda la obra politico-criminal de ROXIN.

${ }^{17}$ Cfr. Instituto de Ciencias Criminales de Frankfurt (ed.). La insostenible situación del Derecho penal, Granada 1999 (edición española a cargo del Area de Derecho penal de la Universidad Pompeu Fabra).

${ }^{18}$ Muy claramente, SCHWIND, Kriminologie. Eine praxisorientierte Einführung mit Beispielen, $5^{2}$ ed., Heidelberg 1993, § $1 n^{2}$ marg. 38-39.

19 MEZGER, Kriminalpolitik und ihre kriminologischen Grundlagen, $3^{3}$ ed., Stuttgart 1944, p. 3 habla del "conjunto de medidas estatales para la prevención y represión del delito"; también SCHWIND, Kriminologie, $5^{2}$ ed., § $1 \mathrm{n}^{2}$ marg. 38. Pero lo cierto es que el Estado cede (o impone) en determinados casos medidas de prevención del delito a sujetos privados, por lo que me parece procedente definir la Política Criminal en términos 
conjunto de principios teóricos que habrían de dotar de una base racional ${ }^{20}$ a la referida praxis ${ }^{21}$ de lucha contra el delito; en donde la clave radica precisamente en determinar qué significa "racional" y cuáles pueden ser los criterios de racionalidad.

2. En todo caso, es lo cierto que tales principios de la Política criminal se concretan en la adopción de diversas formas de evitación del delito (estrictamente preventivas unas; represivo-preventivas, las otras $)^{22}$. En buena medida, la Política criminal se manifiesta en una serie de instrumentos que deben asociarse nominal o fácticamente a la producción presente o futura del delito en orden a evitar que éste se produzca o se reitere ${ }^{23}$. Así contemplado, pueden realizarse dos afirmaciones. Por un lado, que desde luego la Política criminal no se agota en medidas jurídico-penales ${ }^{24}$. Por otro lado, sin embargo, que, aunque la Política Criminal se configure en términos más amplios, todo el Derecho penal se integra en la Política criminal. Así, para el penalista existe una práctica identificación entre la teoría de los principios de la Política Criminal y la de los fines (y medios) del Derecho penal. Ello no debe extrañar. El Derecho penal es expresión de una Política criminal $^{25}$. Asi, la discusión sobre los fines del Derecho penal y sobre los medios precisos para alcanzar tales fines no puede ser más que una

más amplios. KAISER, Kriminologie. Eine Einführung in die Grundlagen, $9^{2}$ ed., Heidelberg 1993, p. 643, reduce la Política criminal a las medidas que tienen lugar a través del sistema del Derecho penal, lo que coincide con el concepto más estricto, también mencionado por Mezger.

${ }^{20}$ PALAZZO, "La politica criminale nell'Italia republicana", en VIOLANTE (ed,), Storia d'Italia, Annali 12, La Criminalitá, Torino 1997, pp. 851 y ss., 851.

${ }^{21}$ KAISER, Kriminologie, $9^{2}$ ed., p. 643, habla de de un "control óptimo del delito"

${ }^{22}$ Para cuya configuración parece ineludible el recurso a la criminología: KAISER, Kriminologie. $9^{2}$ ed., p. 646 y ss.

${ }^{23}$ Por tanto, en realidad, la Política criminal se integra de medidas de prevención primaria (dirigidas a limitar la producción de las causas del delito, ya sea por política económica, social, cultural, estabilización de la conciencia jurídica, etc.). prevención secundaria ( que pretende intimidar al delincuente de modo normativo o fáctico, así como aleccionar a la víctima potencial) y prevención terciaria (dedicada a combatir la reincidencia). Sobre ello, por todos, SCHWIND, Kriminologie, $5^{3}$ ed., $\S 1 \mathrm{n}^{2}$ marg. 40; KUNZ, Kriminologie, Bern/Stuttgart/Wien 1994. pp. $268-269 n^{2}$ marg. 9.

${ }^{24}$ PALAZZO, en VIOLANTE (ed.), Annali 12, p. 852.

${ }^{25}$ Esto es, por un lado, la propia existencia del Derecho penal estatal expresa una opción político-criminal (precisamente, la que pasa por la definición de determinados hechos como delitos y por la atribución al Estado del monopolio de su represión). Por otro lado, un Derecho penal concreto (con su regulación legal y también con su re-construcción dogmática y aplicación práctica) es expresión de una determinada orientación político-criminal dentro de la línea general acogida. 
discusión político-criminal ${ }^{26}$ Y la vocación de la discusión político-criminal es, en último término ${ }^{27}$, la reforma del Derecho penal ${ }^{28}$.

3. Entre los principios de la Política Criminal ocupan un lugar primordial los que rigen la propia calificación de un hecho como delito -y no como hecho antisocial jurídicamente no prohibido, ilícito civil o ilícito administrativo-. En otras palabras, la propia definición de cuáles son los delitos constituye competencia de la Política criminal: cuántas son las conductas que cabe racionalmente calificar como delictivas ${ }^{29}$. Y ello, no sólo en cuanto a lo relativo a qué bienes jurídicos merecen y precisan de protección penal, sino también en cuanto a qué clase de conductas describen riesgos penalmente relevantes: tentativas, hechos imprudentes, hechos en comisión por omisión; etc. En este punto se muestra una de las características fundamentales de la Política criminal: ésta aparece como un sistema que se autodefine. Ello determina la necesidad de abordar el problema de los límites exteriores a autodefinición de la Política criminal: no ya sólo a la del legislador, sino también a la del propio constituyente. En otras palabras, la decisión acerca de si cualquier conducta puede ser definida en un momento dado como delictiva ${ }^{30}$.

4. Es asimismo competencia de la Política criminal la determinación de cómo es el delito; esto es, de cuáles son sus rasgos estructurales característicos. Así, si el delito es un "modo de ser", o un síntoma, o un estado o, por el contrario, un hecho. $Y$, a partir de esta última constatación, cuáles deben ser los elementos integrantes de ese hecho. Obsérvese que, desde el punto de vista adoptado, la teoría del delito no deja de ser un eslabón más de toda la Política criminal $^{31}$. Lo que pone de relieve hasta qué punto es cierta la afirmación de que también la ciencia del Derecho penal, también la propia dogmática de la teoría jurídica del delito, realiza política criminal.

${ }^{26}$ BACKES, "Kriminalpolitik ohne Legitimität", KritV 1986, pp. 315 ss., 315: "...auch Kriminalpolitik, verstanden als Rechtspolitik auf dem Gebiet der Strafrechtspflege, bleibt an strafrechtliche Prinzipien und grundgesetzliche Vorgaben gebunden. Daraus folgt weiter: Einer Kriminalpolitik, die solche Prinzipien und Vorgaben mißachten würde, fehlte selbst dann die Legitimität, wenn sie sich auf eine gesetzliche Grundlage stützen oder eine parlamentarische Mehrheit für ein entsprechendes Gesetz beschaffen könnte".

${ }^{27}$ Aunque la discusión político-criminal cumple también una función muy importante en el ámbito de la "lex lata", se le suele atribuir un papel sobre todo en el ámbito de la "lex ferenda".

${ }^{28}$ KAISER, Kriminologie, $9^{3}$ ed., p. 643.

${ }^{29}$ PALAZZO, en VIOLANTE (ed.). Annali 12, p. 853: la criminalidad no constituye un a priori de la Política criminal, sino que la individualización y la definición legal de la criminalidad es uno de los cometidos de la Política criminal.

${ }^{30}$ El carácter valorativo de la Politica Criminal, hoy asumido de modo general, es subrayado ya por MEZGER, Kriminalpolitik, $3^{2}$ ed., p. 241

31 TIEDEMANN, "Stand und Tendenzen von Strafrechtswissenschaft und Kriminologie in der Bundesrepublik Deutschland", JZ 1980, p. 489 ss., 490: "...Strafrechtsdogmatik eine wesentliche und unersetzliche nämlich die Freiheit des einzelnen gegenüber dem strafenden Staat sichernde Funktion hat". 


\section{La racionalidad de la Política criminal y la orientación personalista.}

1. Lo anterior pone de manifiesto, que lo esencial de cuantas cuestiones previas deben abordarse al acometer el estudio de la Política criminal, es la relativa al modo de determinar la racionalidad que le es propia. Concretamente, la de si existen criterios materiales $^{32}$ de correción a los que, de algún modo, se halla vinculado el legislador a la hora de tomar una decisión político-criminal concreta 0 , por el contrario, la política criminal pertenece al ámbito de lo disponible ${ }^{33}$, de modo que se configura en términos absolutamente relativistas.

2. Al respecto, es cierto que se ha tratado de buscar una legitimación dotada de cierta permanencia en los principios de necesidad y proporcionalidad. Es decir, que, en el punto de partida, se ha sentado la premisa de que las decisiones político-criminales suponen un mal para alguien, mal que sólo cabe infligír de modo subsidiario (esto es, si la finalidad perseguida no puede obtenerse de un modo menos dañoso) y además, de modo proporcionado (esto es, de manera que el daño causado sea adecuado al fin pretendido, no cause un daño mayor que el que evita).

3.Con todo, no es posible obviar la relativa "vacuidad" de los dos referidos principios de necesidad (en el sentido de subsidiariedad) y de proporcionalidad. Pues en ambos, es preciso efectuar una comparación: en el primer caso, entre la alternativa de protección elegida y otras alternativas posibles, para valorar si aquélla por la que se opta es efectivamente menos lesiva que las demás; en el segundo caso, entre el interés protegido y el interés lesionado, para valorar si precisamente el protegido es de mayor valor que el lesionado o no. Así, dos sistemas que acojan como principios estructurales fundamentadores de su política criminal (o de otras intervenciones estatales) los de necesidad y proporcionalidad, pueden llegar a conclusiones absolutamente dispares a la hora de resolver -ya en el plano legislativo- determinados problemas. Pues lo decisivo con ser esto importante- no es la acogida (por cierto, bastante generalizada, hasta el punto de que podría atribuírseles un estatuto quasi-lógico) de tales principios, sino los criterios de valoración de los intereses en presencia, a partir de los cuales, puede sostenerse que una intervención es subsidiaria de otra y proporcionada a la consecución de un determinado objetivo.

32 A juicio de NEUMANN, "Positivistische Rechtsquellenlehre und naturrechtliche Methode, Zum Alltagsnaturrecht in der juristischen Argumentation", en DREIER (Hrsg.), Rechtspositivismus und Wertbezug des Rechts, Stuttgart 1990, pp. 141 y ss, 141, en un ordenamiento jurídico como el de la Ley fundamental alemana, en el que se han positivizado las exigencias centrales del Derecho natural, "die materielle Inhaltskontrolle von Normen (kann) weithin in der Form einer Konsistenzprüfung des Rechtssystems durchgeführt werden. Die Frage, ob eine Norm wegen Unvereinbarkeit mit überpositiven Normen ungültig sein kann, spielt für die Rechtspraxis heute keine Rolle".

${ }^{33}$ ASHWORTH, Principles of Criminal Law, $2^{3}$ ed, Oxford 1995, p. 55: "The contours of criminal law are not given, but are politically contingent". 
4. Lo problemático es, entonces, el método para la determinación del valor relativo de los bienes en juego en el escenario social. Sólo a partir de ahí cabe probablemente definir determinadas lesiones de algunos de ellos como delictivas ( $y$ legitimarlo por razones de proporcionalidad y necesidad: merecimiento y necesidad de pena) y, asimismo, configurar la sanción aplicable apelando asimismo a consideraciones de merecimiento y necesidad. Al respecto, cabe adoptar métodos relativistas. Así, según un punto de vista, el valor relativo de los bienes que se manifiestan en la interacción social sería una cuestión que decidirían los propios integrantes del grupo social sobre la base de un criterio procedimental comunicativo, que se entiende de modo diverso según los autores (teorías del consenso; ética del discurso). El producto de esta propuesta sería un relativismo individualista de base liberal. Según otro punto de vista, dicho valor vendría dado por la propia constitución social, que no se conforma de modo esencial por dicho consenso, sino más bien esencialmente por una determinada tradición cultural; a lo que algunos añaden la idea de que en dicha configuración prima el aspecto funcionalista relativo a la autoconservación del grupo social. El producto de esta propuesta sería un relativismo comunitarista de base sociocultural, eventualmente funcionalista.

5. Poca duda cabe acerca de que el debate actual se suscita entre los dos puntos de vista señalados. Pero obsérvese que ambos - ciertamente, con distinta entidad- se mueven en el ámbito del relativismo. De ahí que la pregunta sea si no cabe establecer criterios de ponderación de los valores en juego que gocen de validez universal, de modo que se fije -aunque sólo sea eso- un marco de indisponibilidad para las políticas criminales de signo relativista (ya consensualista, ya culturalista). Las preguntas que habría que abordar, en lo que a nosotros aquí nos interesa, son las siguientes: ¿hay conductas que necesariamente deben ser prohibidas bajo pena ( $y$ eventualmente bajo una pena determinada)? y, viceversa, ¿hay conductas que de ningún modo pueden ser prohibidas bajo pena?. Si fuera posible dar a estas preguntas una respuesta afirmativa (y no relativa), entonces estaríamos admitiendo la existencia de un ámbito, por muy limitado que este sea, indisponible de la política criminal ("malum/bonum in se ipsum"), más allá de los diversos "mala quia prohibita" relativos al consenso social existente en un momento dado o a la influencia de una cultura dada.

6. Evidentemente, en lo anterior late una propuesta universalista. Sin embargo, ello no implica negar radicalmente toda posibilidad de particularismo o diversidad cultural (que, según se dice, es el signo de la postmodernidad, frente a las pretensiones uniformizadoras de la modernidad). Se trata, simplemente, de salvar un mínimo, frente al cual no cabría esgrimir ni el consenso coyuntural de una sociedad dada ni el relativismo cultural. Así, por ejemplo, no cabría esgrimir una "teoría de la relatividad de los derechos humanos fundamentales" (vida, integridad, libertad ambulatoria, otras libertades), o una excepción cultural en este punto. 
7. Parecen manifestarse signos de la voluntad de reconocer la existencia de principios indisponibles. La creciente aparición de excepciones al principio de territorialidad e imposición de un principio de justicia penal universal (que de los crímenes contra la humanidad está pasando a abarcar buena parte de la criminalidad organizada); el cuestionamiento de leyes como la "Ley de punto final" argentina; la sanción de conductas de "turismo sexual" con menores cometidas en el extranjero; o la Política criminal en países islámicos o en Asia.

8. Así pues, sin olvidar la evidente "relatividad" o "condicionalidad sociocultural" del Derecho penal, se trata de enmarcar la Política criminal en el contexto del concepto de persona, su dignidad y sus derechos fundamentales; en definitiva, en el marco de una fundamentación objetiva ${ }^{34}$. Seguramente sólo desde estas premisas, que por otro lado, son obviamente compatibles con el reconocimiento de la dificultad de acceder de modo inequívoco al objeto de conocimiento, será posible reconstruir un modelo satisfactorio de Política criminal.

${ }^{34}$ Este punto de vista es perfectamente compatible con el normativismo y, más aún, con un normativismo "culturalista"; es decir, con un normativismo que parte de que los modelos político-criminales tienen mucho que ver con las diversas culturas, o civilizaciones, y por tanto, se configurarán de modo diverso en cada una de ellas. Lo que por mi parte no suscribiría sería un normativismo que niegue la existencia de todo marco de referencia externo: de la obvia pluralidad cultural no puede llegarse a un absoluto ( $y$, a mi entender, inaceptable) relativismo cultural. Esa sería la tesis, según parece, de un "comunitarista" (¿?) como ALASDAIR MACINTYRE, cuando indica que sólo puede hablarse de "the practical rationality of-this-or-that-tradition and the justice of this-or-thattradition" (citado apud TÖNNIES, Der westliche Universalismus. Eine Verteidigung klassischer Positionen. Opladen 1995, p. 224).

Esto último es, en cualquier caso, lo que se manifestó, ciertamente en el plano puramente político, en la Conferencia Mundial sobre Derechos Humanos de la ONU, celebrada en Viena en junio de 1993. Según señala S.P. HUNTINGTON, El choque de civilizaciones y la reconfiguración del orden mundial (trad, Tosaus Abadia), Barcelona 1997, p. 233, ya dos meses antes de la conferencia, los paises asiáticos se reunieron en Bangkok y aprobaron una declaración que insistía en que los derechos humanos se debian considerar "en el marco... de las particularidades nacionales y regionales y en el contexto de los diversos bagajes históricos, religiosos y culturales". lo que dió lugar a que el documento final resulte, desde perspectivas de derechos humanos, "imperfecto y contradictorio". Ultimamente, la prensa se ha hecho eco de las manifestaciones del presidente chino Jiang Zemín en relación con lo que él denomina "teoría de la relatividad de los derechos humanos".

Obsérvese como, en el planteamiento reflejado, el marco queda roto desde perspectivas de relativismo culturalista. Claro está que puede objetarse que la derivación de los derechos humanos de la noción de persona constituye un vicio lógico (una falacia, puesto que del ser deriva el deber ser), de modo que, tales derechos sólo pueden sustentarse en un normativismo (a saber, la concepción occidental acerca de lo que es debido al hombre por el hecho de serlo). Pero obsérvese que en tal "normativismo" se acoge precisamente la fundamentación ontológica: los derechos humanos no son producto de una atribución, porque lo dispongan las constituciones, o porque exista consenso sobre su aceptación, sino que son "reconocidos", porque son "preexistentes" y un cambio de consenso, no seria suficiente para rechazarlos. Obviamente en tal premisa -la dimensión ontológica de los derechos humanos- (la persona tiene derechos por serlo)se halla el punto de partida de la pretensión de universalización que es inherente a la teoría. Si se estima que incluso esto no es sino de un modelo normativista más (marcado por una determinada tradición cultural), la conclusión obvia es que no existiría un marco ontológico representado por la persona y sus derechos, con lo que la política criminal podría moverse en un normativismo ( $y$, por ello, relativismo) culturalista sin referente externo (y, por tanto, $\sin$ fronteras). Sobre la necesariedad de acudir a un fundamento objetivo en materia de derechos humanos, OLLERO TASSARA, ¿Tiene razón el Derecho?, Madrid 1997, p. 390, 396-397 